\title{
PERBEDAAN KEKERASAN PERMUKAAN BAHAN RESTORASI RESIN KOMPOSIT NANOFILLERYANG DIRENDAM DALAM MINUMAN RINGAN BERKARBONASI DAN MINUMAN BERALKOHOL
}

\author{
Nurul Ikhsan ${ }^{1}$, Nila Kasuma ${ }^{2}$, Didin Kustantiningtyastuti ${ }^{3}$ \\ Fakultas Kedokteran Gigi, Universitas Andalas, Padang, Sumatera Barat, Indonesia \\ Departemen Periodonti, Fakultas Kedokteran Gigi, Universitas Andalas, Padang, Sumatera Barat, Indonesia
}

\begin{abstract}
Resin composite is dental material filling that is commonly used in dentistry which has good physical properties, mechanical and aesthetics. The properties that have an important role in the resistance of the composite resin surface hardness which directly involved when contact with food, drink and salivary. The purpose of this research is to evaluate the effect of carbonated soft drink and alcoholic beverages on the surface hardness of nanofiller composite resin.The method used in this research is post test only control group design. Samples were made using the mold made of stainless steel, with diameter of 6mm and tick of $2 \mathrm{~mm}$, composite was manipulated according to the manufacture's instructions, and then immersed in aquades, carbonated soft drink and alcoholic beverages for 18 hours in a temperature of $37^{\circ} \mathrm{C}$. Samples were tested using Vickers Hardness Test. Data analysis using Kruskal-Walis test.The result show that the nanofiller composite resin which immersed in alcoholic beverages has higher surface $(81,04 \pm 10,44$ VHN), whreas the composite which immersed in aquades and carbonated soft drink has the surface hardness $(70,20 \pm 16,6$ dan $71,10 \pm 15,96 \mathrm{VHN})$. The result of data analysis showed that the data are not distributed normally and showed a significant value of $p>0,05$. From this research can be concluded that there is no significant differences in surface hardness of nanofiller composite resin which immersed in carbonated soft drink and alcoholic beverages.
\end{abstract}

Keywords: Resin Komposit, nanofiller, surface hardness, mechanical properties.

Affiliasi penulis: Fakultas Kedokteran Gigi,

Universitas Andalas, Padang, Sumatera Barat, Indonesia

Korespondensi: Audia Tria Putri

e-mail: silmigusdayuni38@yahoo.co.id

\section{PENDAHULUAN}

Resin komposit dikenal sebagai salah satu bahan restorasi yang sering digunakan di bidang kedokteran gigi yang diperkenalkan oleh Bowen pada awal tahun 1960-an. ${ }^{1,2}$ Setelah mengalami banyak perkembangan dari akhir tahun 1950-an sampai awal 1960an, akhirnya pada awal tahun 1970-an resin komposit telah resmi menggantikan resin tanpa bahan pengisi untuk restorasi gigi. $^{3}$ Komposit merupakan gabungan dari dua jenis atau lebih material yang setiap materialnya memiliki kontribusi terhadap seluruh sifat dari komposit. ${ }^{1}$

Resin berbasis komposit yang digunakan dalam kedokteran gigi memiliki tiga komponen utama yakni matriks resin, bahan pengisi, dan bahan coupling. ${ }^{1,2}$ Resin Komposit memiliki beberapa sifat fisik dan mekanik. Sifat fisiknya terdiri dari polymerization shrinkage, penyerapan air, dan kelarutan. Sifat mekanisnya terdiri dari kekuatan 
fleksural, modulus elastisitas, kekasaran permukaan, dan kekerasan. ${ }^{3,4}$ Salah satu sifat dari resin komposit yang sangat penting yakni kekerasan dan kelarutan. Kekerasan dan kelarutan ini dapat digunakan sebagai parameter untuk mengetahui kemampuan suatu bahan dalam menahan sifat abrasif dan erosif yang selalu terjadi saat mengunyah dan menggosok gigi. ${ }^{3,4,5}$

Jenis resin komposit dibedakan berdasarkan ukuran partikel filler penyusunnya seperti macrofiller, microfiller, hybrid, dan nanofiller. Semakin besar ukuran partikel filler maka ikatannya makin lemah sehingga mudah terjadi abrasi saat makan, minum atau penyikatan gigi karena hanya resin matriks yang tertinggal dan juga menyebabkan permukaan restorasi menjadi kasar. ${ }^{3,6}$

Peningkatan permintaan dalam estetik kedokteran gigi telah menuntun perkembangan bahan restorasi resin komposit dengan peningkatan sifat fisik, mekanik, estetik, dan clinical longevity seperti yang dapat ditemukan pada jenis resin komposit nanofiller. ${ }^{7}$ Resin komposit nanofiller dapat digunakan untuk restorasi gigi anterior atau pun posterior karena memiliki retensi polis yang tinggi dan memiliki sifat mekanis yang sangat bagus dan sesuai untuk perlindungan terhadap tekanan tinggi pada daerah restorasi. ${ }^{7,8}$ Nanofiller diyakini mempunyai kandungan filler yang tinggi, mudah diaplikasikan serta dapat bertahan lama, hal ini yang menjadi alasan resin komposit nanofiller banyak digunakan di kedokteran gigi. ${ }^{7,9-10}$

Minuman ringan yang sering dikonsumsi masyarakat Indonesia merupakan minuman yang tidak mengandung alkohol, salah satunya minuman berkarbonasi. $^{11,12}$ Minuman ringan mengandung bahan pemanis, asam (acidulants), dan bahan perasa. Salah satu contoh yang termasuk minuman ringan adalah cola, lemon, orange, kopi bir dan anggur. ${ }^{13}$ Menurut Jacobson (2003), rasa manis dalam sekaleng minuman ringan setara dengan tujuh sendok teh gula pasir. Pada survei tahun 1997, diketahui 44\% lelaki di Amerika Serikat mengonsumsi 34 sendok teh gula/ hari akibat konsumsi minuman ringan. Sebaliknya, $\quad 40 \%$ perempuan mengkonsumsi 24 sendok teh gula/hari. Hal ini akan mempengaruhi keasaman rongga mulut seseorang. Semakin sering gigi berkontak dengan minuman ringan yang mengandung gula akan menyebabkan keasaman rongga mulut semakin menurun, maka makin besar pula terjadinya kelarutan mineral email gigi dalam saliva. $^{14}$ Kandungan zat 
pemberi asam (acidulants) pada minuman ringan yang bersifat sebagai pelarut, dapat menyebabkan terjadinya demineralisasi dan penurunan kekerasan pada enamel dan dentin gigi. ${ }^{29,37,39}$

Minuman ringan mempunyai pengaruh buruk terhadap bahan restorasi gigi. Yanikoglu dkk (2009) dalam penelitiannya menemukan penurunan kekerasan permukaan resin komposit setelah dilakukan perendaman dalam minuman ringan berkarbonasi. ${ }^{15}$ Pada tahun 2011 Hamouda juga melakukan penelitian terhadap kekerasan, kekasaran, dan kelarutan beberapa bahan restorasi estetik terhadap beberapa jenis minuman dengan $\mathrm{pH}$ yang rendah dan mengandung asam sitrat. Hasilnya terdapat penurunan kekerasan, peningkatan kekasaran, dan kelarutan bahan restorasi. ${ }^{16}$

\section{Organisasi Kesehatan Dunia} (WHO) menyatakan bahwa individu berusia diatas 15 tahun jumlah konsumsi minuman beralkohol 6,2 liter setiap tahun, dengan tingkat konsumsi 13,5 gram perhari. Secara global, 50,1\% dari total konsumsi alkohol tercatat pada jenis spiritus dan urutan kedua 34,8\% diduduki oleh minuman jenis bir. Dari kedua jenis minuman beralkohol tingkat konsumsi bir pada daerah Asia Tenggara termasuk tinggi dari pada daerah lainnya di dunia. ${ }^{17}$ Riskesdas tahun 2007 menunjukkan proporsi jenis alkool yang dikonsumsi penduduk laki-laki usia 15 tahun ke atas dalam 1 bulan terakhir di perkotaan di Indonesia adala 33,6 \% bir, 14,4 \% likuor, $27,1 \%$ wine, $25,0 \%$ trad berdasarkan hasil survei dari 660.349 individu. Proporsi tingkat konsumsi alkohol pada penduduk laki - laki usia 15 tahun ke atas dalam 1 bulan terakhir di provinsi Sumatera Barat berada pada level cukup tinggi, yakni 48,7 \% bir, $31,9 \%$ likuor, $11,9 \%$ wine, dan $7,5 \%$ trad. $^{18}$

Minuman beralkohol diproses melalui pengenceran minuman yang mengandung etanol. Minuman beralkohol dapat merusak tumpatan pada enamel gigi yang perlahan membuatnya keropos, karena memiliki sifat asam dan sebagai pelarut. Terutama mempengaruhi warna dan mengikis enamel gigi karena keasaman dari minuman beralkohol. Resti (2011) melakukan penelitian pengaruh etanol 0-5\% terhadap kekerasan permukaan resin komposit hybrid yang direndam selama 15 menit. Hasilnya menyatakan semakin lama waktu perendaman resin komposit hybrid maka nilai kekerasan permukaannya akan semakin menurun. ${ }^{19}$ Pada tahun 2015 Vanessa, dkk juga melakukan penelitian gambaran kekuatan tekan bahan tumpatan Semen Ionomer Kaca yang direndam 
dalam minuman beralkohol dengan variasi kandungan alkohol 5\%, 10\%, 40\% selama 24 jam. Hasilnya berbanding terbalik dengan penelitian sebelumnya yaitu terdapat peningkatan kekuatan tekan dari Semen Ionomer Kaca, peningkatan nilai terjadi ketika sampel SIK direndam dalam minuman beralkohol dengan konsentrasi tinggi yakni $40 \%$ dengan hasil uji tekan 2,58 $\mathrm{MPa}^{35}$

Sejauh yang peneliti ketahui belum ada penelitian mengenai perbedaan kekerasan permukaan bahan restorasi resin komposit nanofiller yang direndam dalam minuman ringan berkarbonasi dan minuman beralkohol. Berdasarkan hal tersebut, peneliti tertarik untuk mengetahui perbedaan kekerasan permukaan bahan restorasi resin komposit nanofiller yang direndam dalam minuman ringan berkarbonasi dan minuman beralkohol.

\section{METODE PENELITIAN}

Penelitian ini merupakan penelitian eksperimental laboratoris dengan menggunakan post test only control group desain. Penelitian ini dilaksanakan mulai bulan Februari 2016 hingga bulan Maret 2016 dan dilaksanakan pada Laboratorium Mikrobiologi Fakultas Farmasi dan Laboratorium Matalurgi Program Studi
Teknik Mesin Fakultas Teknik Universitas Andalas. Populasi penelitian adalah tambalan resin komposit nanofiller dengan merek dagang Z350XT dari 3M. Sampel penelitian adalah hasil cetakan tambalan resin komposit nanofiller berbentuk cakram dengan diameter $6 \mathrm{~mm}$ dan tebal $2 \mathrm{~mm}$, dengan keseluruhan sampel berjumlah 27 yang dibagi menjadi 3 kelompok.

Keseluruhan spesimen berjumlah 27 buah yang dibagi menjadi 3 kelompok, yaitu 9 buah spesimen direndam dalam aquades sebagai kontrol, 9 buah spesimen direndam dalam minuman ringan berkarbonasi, dan 9 buah spesimen direndam dalam minuman beralkohol yang masing masingnya direndam selama 18 jam. Pengujian kekerasan sampel, pengujian dilakukan dengan alat uji kekerasan Vickers Hardness Test dengan memberikan tekanan sebesar 100gf selama 15 detik. Pengujian kekerasan pada tiap-tiap sampel dilakukan pada bidang atas sampel. Pada bidang tersebut dilakukan 3 titik pengukuran. Titik pengukuran terletak segaris pada 
Tabel 5.1 Hasil Pengukuran Nilai Kekerasan Permukaan Resin Komposit Nanofiller pada setiap kelompok perlakuan (VHN)

\begin{tabular}{|c|c|c|c|}
\hline \multirow[b]{2}{*}{ Sampel } & \multicolumn{3}{|c|}{ Kekerasan (VHN) } \\
\hline & $\begin{array}{l}\text { Kelompok } \\
\text { Aquades }\end{array}$ & $\begin{array}{c}\text { Kelompok } \\
\text { Minuman } \\
\text { Ringan } \\
\text { Berkarbonasi }\end{array}$ & $\begin{array}{c}\text { Kelompok } \\
\text { Minuman } \\
\text { Beralkoho }\end{array}$ \\
\hline 1 & 54,37 & 85,60 & 84,20 \\
\hline 2 & 83,03 & 77,40 & 78,40 \\
\hline 3 & $82 ! 70$ & 58,70 & 88,80 \\
\hline 4 & 83,50 & 53,30 & 57,50 \\
\hline 5 & 36,53 & 76,60 & 87,30 \\
\hline 6 & 76,63 & 43,00 & 84,90 \\
\hline 7 & 57,90 & 71,70 & 74,20 \\
\hline 8 & 80,60 & 85,20 & 92,90 \\
\hline 9 & 76,50 & 88,40 & 81,20 \\
\hline Rata-rata & 70,20 & 71,10 & 81,04 \\
\hline
\end{tabular}

diameter sampel yaitu pada titik sentral sampel, dan pada $1 \mathrm{~mm}$ dari masingmasing tepi sampel pada permukaan sampel yang disinari.

\section{HASIL PENELITIAN}

Berdasarkan hasil pengujian kekerasan permukaan pada sampel bahan restorasi resin komposit nanofiller yang terdiri dari 3 kelompok perlakuan dengan besar sampel 9 buah untuk setiap kelompok perlakuan dan setiap sampel memiliki 3 titik pengukuran. Hasil pengukuran yang diperoleh sesuai dengan rumus perhitungan nilai kekerasan permukaan resin komposit nanofiller yang dilakukan secara digital oleh alat Vickers Hardness Test. Hasil pengukuran sampel dapat dilihat pada tabel 5.1.

Dari tabel 5.1 terlihat bahwa terdapat perbedaan rata-rata kekerasan permukaan resin komposit nanofiller yang direndam dalam aquades, minuman berkarbonasi dan minuman beralkohol.
Nilai rata-rata kekerasan permukaan pada kelompok resin komposit nanofiller yang direndam dalam aquades lebih rendah yaitu 70,20 VHN, sementara kelompok resin komposit nanofiller yang direndam dalam minuman beralkohol memiliki rata-rata kekerasan permukaan yang lebih tinggi yaitu 81,04 VHN.

Sebelum dilakukan pengujian lebih lanjut untuk mengetahui pengaruh minuman ringan berkarbonasi dan minuman beralkohol terhadap kekerasan permukaan resin komposit nanofiller, terlebih dahulu dilakukan uji normalitas pada masing-masing kelompok dengan menggunakan uji Shapiro-Wilk. Hasilnya terdapat satu kelompok penelitian mempunyai nilai $\mathrm{p}$ lebih kecil dari 0,05 $(\mathrm{p}<0,05)$ yaitu $\mathrm{p}=0,023$ yang berarti data pada seluruh kelompok perlakuan tersebut tidak terdistribusi dengan normal, selanjutnya setelah dilakukan uji normalitas, terlihat bahwa data tidak normal maka dilakukan uji non parametrik yaitu uji Kruskal Wallis untuk mengetahui apakah ada pengaruh minuman ringan berkarbonasi dan minuman beralkohol terhadap kekerasan permukaan resin komposit nanofiller. 
Tabel 5.2 Hasil Uji Kruskal-wallis Perbedaan Kekerasan Permukaan Resin Komposit Nanofiller yang direndam dalam Minuman Ringan Berkarbonasi dan Minuman Beralkohol

\begin{tabular}{ccccc}
\hline $\begin{array}{c}\text { Kelompok } \\
\text { Perlakuan }\end{array}$ & $\mathrm{N}$ & $\begin{array}{c}\text { Median } \\
\text { (minimum- } \\
\text { maksimum) }\end{array}$ & Mean \pm SD & p \\
\hline Aquades & 9 & $76(36-83)$ & $70,12 \pm 16,60$ & \\
Berkarbonasi & 9 & $76(43-88)$ & $71,10 \pm 15,96$ & 0,169 \\
Beralkohol & 9 & $84(57-92)$ & $81,04 \pm 10,44$ & \\
\hline Total & 27 & & & \\
\hline
\end{tabular}

Uji Kruskal Wallis menunjukkan $\mathrm{p}=$ $0,169$ ( $\mathrm{p}>0,05)$ yang artinya tidak terdapat perbedaan yang bermakna antara kelompok perlakuan yang diuji. Sehingga hipotesis nol $\left(\mathrm{H}_{0}\right)$ dapat diterima dan $\mathrm{Ha}$ tidak dapat diterima atau ditolak, maka perlu dilakukan uji lebih lanjut menggunakan uji multipel komparasi Mann-Whitney untuk melihat besarnya perbedaan dari setiap perlakuan.

Tabel 5.3 Hasil Uji Multipel Komparasi Mann-Whitney Perbedaan Kekerasan Permukaan Resin Komposit Nanofiller yang direndam dalam Minuman Ringan Berkarbonasi dan Minuman Beralkohol

\begin{tabular}{|c|c|}
\hline Kelompok & $\mathrm{p}$ \\
\hline $\begin{array}{l}\text { Aquades dan Minuman } \\
\text { Berkarbonasi }\end{array}$ & 0,796 \\
\hline $\begin{array}{c}\text { Aquades dan Minuman } \\
\text { Beralkohol }\end{array}$ & 0,077 \\
\hline $\begin{array}{c}\text { Minuman Berkarbonasi dan } \\
\text { Beralkohol }\end{array}$ & 0,190 \\
\hline
\end{tabular}

Dari Tabel 5.3 dapat dilihat perbedaan antara kelompok perendaman dalam aquades (kontrol) dengan kelompok minuman berkarbonasi sebesar $\mathrm{p}=0,796$, perbedaan antara kelompok perendaman dalam aquades (kontrol) dengan kelompok minuman beralkohhol sebesar $\mathrm{p}=0,077$ dan perbedaan antara kelompok perendaman dalam minuman berkarbonasi dan minuman beralkohol sebesar $\mathrm{p}=0,190$. Hasil uji multipel komparasi Mann-Whitney perbedaan kekerasan permukaan resin komposit nanofiller yang direndam dalam minuman ringan berkarbonasi dan minuman beralkohol, menunjukkan bahwa tidak terdapat perbedaan yang signifikan atau bermakna pada kelompok perendaman dalam aquades dengan kelompok perendaman dalam minuman berkarbonasi, kelompok perendaman dalam aquades dengan kelompok perendaman dalam minuman beralkohol, dan kelompok perendaman dalam minuman berkarbonasi dengan kelompok perendaman dalam minuman beralkohol.

\section{PEMBAHASAN}

Pada penelitian ini dilakukan uji kekerasan pada 27 sampel resin komposit nanofiller yang direndam dalam aquades, minuman ringan berkarbonasi dan minuman beralkohol. Penelitian dilakukan di laboratorium teknik metalurgi fisik Universitas Andalas, sampel diuji kekerasan permukaannya dengan alat vickers hardness test, didapatkan nilai berupa VHN (vickers hardness number). Berdasarkan hasil penelitian mengenai perbedaan kekerasan permukaan bahan restorasi resin 
komposit nanofiller yang direndam dalam minuman ringan berkarbonasi dan minuman beralkohol, diketahui tidak terdapat perbedaan yang signifikan antara resin komposit nanofiller yang direndam dalam minuman ringan berkarbonasi dan minuman beralkohol dengan nilai p>0,05.

Dari hasil penelitian ini diperoleh nilai rata-rata hasil pengukuran kekerasan permukaan pada sampel resin komposit nanofiller, sebesar 70,20 VHN pada kelompok perendaman dalam aquades (kontrol), 71,10 VHN pada kelompok perendaman dalam minuman ringan berkarbonasi selama 18 jam dan 81,04 VHN pada kelompok perendaman dalam minuman beralkohol selama 18 jam. Nilai perbedaan kekerasan permukaan antara kelompok aquades dengan minuman ringan berkarbonasi sebesar 0,9 VHN, nilai perbedaan kekerasan permukaan antara kelompok aquades dengan minuman beralkohol sebesar 10,84 VHN, dan perbedaan kekerasan permukaan anatara kelompok minuman ringan berkarbonasi dan minuman beralkohol sebesar 9,94 VHN.

Hasil data menunjukkan aquades dan minuman ringan berkarbonasi (minuman cola) meyebabkan perbedaan kekerasan permukaan resin komposit nanofiller lebih besar dibandingkan dengan minuman beralkohol. Perbedaan kekerasan permukaan resin komposit nanofiller yang direndam dalam aquades ini disebabkan sifat penyerapan air pada bahan restorasi. Penyerapan air dapat dipengaruhi oleh konsentrasi, tipe, ukuran dan distribusi dari partikel filler dalam matriks resin. Penyerapan air pada resin komposit nanofiller lebih tinggi dapat disebabkan oleh ukuran dan distribusi dari filler resin komposit nanofiller. Besarnya daerah permukaan dari resin komposit nanofiller yang berasal dari partikel primer yaitu silika bebas (non agglomerated) yang memungkinkan lebih banyak air yang terakumulasi pada interface filler primer dan polimer matriks, yang akan meningkatkan nilai penyerapan air, sehingga air terakumulasi pada interface tersebut dan memungkinkan adanya jalan masuk air ke dalam agregrat. ${ }^{49,50}$

Penyerapan air pada resin komposit nanofiller juga dipengaruhhi oleh monomer matriks resin yang bersifat hidrofilik. TEGDMA adalah salah satu monomer yang memiliki sifat hidrofilik paling besar yaitu $69,51 \mu \mathrm{g} / \mathrm{mm}^{3}$. Sifat hidrofilik ini memungkinkan masuknya air ke dalam polimer matriks dan penggabungan monomer yang akan meningkatkan sifat mekanis resin 
komposit nanofiller. ${ }^{47-50}$ Matriks resin bis-GMA umumnya mempunyai berat molekul yang tinggi sehingga bersifat kental dan lengket, sehingga resin biasanya diencerkan dengan jenis monomer yang memiliki viskositas yang rendah dan dikenal sebagai pengendali viskositas yakni TEGDMA. TEGDMA digunakan untuk menghasilkan resin yang bisa secara maksimal terisi oleh partikel filler. Pengenceran tersebut akan mempengaruhi penyerapan air pada resin komposit. Air yang berkontak dengan permukaan partikel silika, dapat memutuskan ikatan siloxane dan menyebabkan lepasnya ikatan antara partikel bahan pengisi yang dapat meningkatkan hilangnya berat dari resin komposit. Van Noort (2007) menyatakan penerapan air merupakan proses yang lama dan membutuhkan waktu untuk mencapai kesetimbangan. Resin komposit dengan tebal $2 \mathrm{~mm}$ membutuhkan waktu 166 hari untuk mencapai kesetimbangan. ${ }^{1,20}$

Pada penelitiannya Silva et al (2008) menyatakan bahwa resin komposit nanofiller mempunyai solubilitas dan penyerapan saliva yang lebih tinggi dibanding resin komposit hybrid. Resin komposit nanofiller memiliki degradasi yang lebih tinggi dari pada resin komposit hybrid di dalam rongga mulut. $^{5,42}$ Firoozmand (2011) dalam penelitiannya tentang evaluasi resin komposit terhadap penyerapan air, kekerasan dan scanning electron menyatakan terdapat perbedaan yang berarti dari penyerapan air pada resin komposit yang dihubungkan dengan ukuran, bentuk dan konsentrasi dari partikel bahan pengisi anorganik dalam resin komposit. Resin komposit nanofiller menunjukkan nilai penyerapan air yang lebih tinggi dari pada resin komposit microhybrid. ${ }^{43}$

Perbedaan kekerasan permukaan resin komposit nanofiller yang direndam dalam minuman ringan berkarbonasi (minuman cola) memiliki hasil yang sejalan dengan penelitian sebelumnya. Yonikoglu N et al (2009) menyatakan bahwa terdapat perbedaan kekerasan resin komposit yang signifikan setelah perendaman dalam minuman ringan berkarbonasi (coca cola) selama 24 jam. Mckenzie M.A et al (2004) menyatakan terjadinya perbedaan kekerasan resin komposit yang signifikan setelah direndam dalam coca cola selama 1 hari, 1 bulan, 3 bulan, 4 bulan dan 6 bulan. ${ }^{15,37}$ Terjadinya perbedaan kekerasan resin komposit dapat disebabkan oleh berbagai faktor, diantaranya adalah karena 
penyerapan air oleh resin komposit, proses hidrolisis, penurunan $\mathrm{pH}$, serta dampak erosif dari asam yang terkandung dalam minuman ringan berkarbonasi. $^{11,28,37}$ Penyerapan air oleh resin komposit dapat terjadi karena matriks resin bersifat hidrofilik sehingga matriks mampu menyerap air. Selanjutnya akan terjadi peristiwa hidrolisis yang akan merusak ikatan antara silane dan filler, merusak ikatan filler dan matriks dan hidrolisis juga akan mengakibatkan degradasi antar filler. ${ }^{44}$ Hidrolisis ini juga merusak radikal ester yang ditemukan di dalam monomer dimethacrylate seperti Bis-GMA, BisEDMA, UDMA, dan TEGDMA. ${ }^{44,45}$

Faktor lain penyebab terjadinya perbedaan kekerasan permukaan resin komposit akibat perendaman dalam minuman ringan berkarbonasi dapat pula terjadi karena kandungan asam fosfat dan asam sitrat pada minuman ringan berkarbonasi. Zat asam ini ditambahkan ke dalam minuman ringan untuk memberikan sensasi rasa asam yang tajam dan berbeda. Akibatnya minuman ringan berkarbonasi memiliki $\mathrm{pH}$ rendah yang menyebabkan terganggunya integritas permukaan resin komposit dan menurunkan integritas permukaan resin komposit, hal ini yang berdampak pada penurunan kekerasan resin komposit. ${ }^{15,46-}$ 48 Minuman ringan berkarbonasi memiliki $\mathrm{pH}$ yang rendah, $\mathrm{pH}$ minuman pada penelitian ini 2,5 , sehingga terdapat banyak ion $\mathrm{H}^{+}$di dalamnya. Ion-ion $\mathrm{H}^{+}$ yang berasal dari asam fosfat dan asam sitrat ini akan berdifusi ke dalam matriks dan berikatan dengan ion negatif di dalam matriks. Ion-ion $\mathrm{H}^{+}$menyebabkan adanya ion yang bebas terdorong keluar dan terlepas dari ikatan matriks. Terurainya ion-ion dari matriks menyebabkan ikatan kimia tidak stabil dan pada akhirnya matriks juga terurai dan larut. ${ }^{15,46,49} \mathrm{Hal}$ ini yang mengakibatkan terjadinya perbedaan kekerasan permukaan pada sampel yang direndam dalam minuman berkarbonasi.

Perbedaan kekerasan permukaan resin komposit nanofiller yang direndam dalam minuman beralkohol dapat disebabkan oleh kandungan etanol yang terdapat pada minuman tersebut. Gugus $\mathrm{OH}^{-}$dalam etanol akan menyerap molekul air lebih banyak dan akan berdifusi ke dalam matriks resin yang bersifat polar, sehingga menyebabkan molekul resin terpisah akibatnya matriks resin mengalami swelling. Swelling pada resin komposit ini dapat menimbulkan tekanan disekitar bahan pengisi resin komposit, yang mengakibatkan degradasi 
struktur dan putusnya jembatan molekul Si-O-Si yang mengikat partikel dengan silane (coupling agent). Rusaknya jembatan Si-O-Si akan menghasilkan perpindahan proton yang akan membentuk jembatan Si-O, dimana atom $\mathrm{Si}$ - yang tersisa akan berpasangan dengan grup hidroksi dari etanol, hal ini yang menyebabkan terjadinya perbedaan kekerasan permukaan resin komposit nanofiller yang direndam dalam minuman beralkohol. ${ }^{45,50,51}$ Hasil penelitian ini sejalan dengan penelitian sebelumnya yang dilakukan oleh Resti (2011) bahwa terdapat perbedaan kekerasan permukaan resin komposit hybrid yang direndam dalam minuman beralkohol. ${ }^{19}$

\section{KESIMPULAN}

Dari hasil penelitian tentang perbedaan kekerasan permukaan bahan restorasi resin komposit nanofiller yang direndam dalam minuman ringan berkarbonasi dan minuman beralkohol dapat disimpulkan bahwa:

Nilai rata-rata kekerasan permukaan sampel resin komposit nanofiller yang direndam dalam aquades (kontrol) sebesar 70,12 $\pm 16,60$ VHN, sampel resin komposit nanofiller yang direndam dalam minuman ringan berkarbonasi sebesar 71,10 $\pm 15,96$ VHN dan sampel resin komposit nanofiller yang direndam dalam minuman

beralkohol sebesar 81,04 $\pm 10,44$ VHN.

Terdapat perbedaan kekerasan permukaan yang tidak signifikan pada kelompok perendaman dalam aquades (kontrol) dengan kelompok yang direndam dalam minuman ringan berkarbonasi dan minuman beralkohol.

Terdapat perbedaan kekerasan permukaan yang tidak signifikan pada kelompok perendaman dalam minuman ringan berkarbonasi dan minuman beralkohol.

Aquades lebih berpengaruh terhadap kekerasan permukaan resin komposit nanofiller dibandingkan dengan minuman lainnya

\section{KEPUSTAKAAN}

1. Noort RV. Introduction to dental material. Third edition. Elsavier. 2007: 127-43.

2. Sintawati Juretta, Sri Harini Soemartono, Margaretha Suharsini. Pengaruh durasi aplikasi asam fosfat $37 \%$ terhadap kekuatan geser restorasi resin komposit pada email gigi tetap. Indonesian Journal of Dentistry. 2008; 15(2):97-103.

3. Anusavice KJ. Phillips' science of dental material. Edisi X. Alih bahasa. Budiman JA, Purwoko S. Jakarta;EGC. 2010;559;449-60.

4. Powers JM, Ronald L Sakaguchi. Craig's restorative dental material. Twelft Edition. London:Mosby Inc. 2006;77-85;173-77.

5. Da Silva EM, Poskus LT, Guimares JGA. Influence of light-polymerizationmodes on the degree of conversion and mechanical properties o resin composites. A Comparative analysis between a hybrid 
and a nanofilled composite. Operative Dentistry J. 2008;33(3):287-93.

6. Hatrick CD et al. Dental materials: Clinical Applications for Dental Assistants and Dental Hygienists. 2nd Edition. St. Louis:Saunders. 2011:135-39.

7. Rogerio Simoes, Carlos EAB, Eduardo B, Eduardo GM, Hugo MSO, Luciana H, Luis AGP, Roberto Hubler. Evaluation o Mechanical Properties on three nanofilled composites. Stomatogija,Baltic Dental and Maxiloacial Journal. 2012; 14(4):126-30.

8. Mitra SB,Wu D, Holmes BN. An application of nanotechnology in advanced dental material. J Am Dent Assoc. 2003; 13(4):182-90.

9. Cetin AR, Unlu N. One year Clinical Evaluation of Direct Nanofilled and Indirect Composite Restorations in Posterior Teeth. Dent Mater Journal. 2009;28(1):620-6.

10. Suzuki T, Kyoizumi H, Finger WJ, Kanehira M, Endo T, Utterodt A, Hisamitsu H, Komatsu M. Resistance of Nanofill and Nanohybrid Resin Composites to Tooth Brush Abrasion with Calcium Carbonate slurry. Dent Mater Journal. 2005;21(1):708-16.

11. Widodo R. Mengenal minuman ringan berkarbonasi[cited 09:20,5 Desember 2015]. Available from website : http://www.untag-sby.ac.id.

12. Robert P. The New Encyclopedia Britannica. 14th ed. Chicago:Encyclopedia Britannica Inc. 1986.14;752-3.

13. Prasetyo EA. Keasaman minuman ringan menurunkan kekerasan permukaan gigi. Dental Journal. 2005;38(2):60-3.

14. Jacobson. Minuman Ringan dibalik Kenikmatannya Ada Bencana[cited 15:30,7 Desember 2015]. Available from website http://www.itjen.depkes.go.id.

15. Yonikoglu N, Duyumus ZY, Yilmaz B. Effect of Different Solution on The Surface Hardness of Resin Materials. Dent Mater J. 2009;28(3): 344-51.

16. Hamouda IM. Effects of Various Beverages on Hardness, roughhness and solubillity of Esthetic Restoration Materials. Journal of Esthetic and Restorative Dentistry. 2011;12(1):315-22.

17. WHO Global Status report on alcohol \& health 2014[cited 16:00,7 Desember
2015]. Available from website http://www.who.int/substance_abuse/publi cations/global_alcohol_report/en.pdf.

18. Riskesdas SKRT, Departemen Kesehatan RI 2007[cited 16:30,7 Desember 2015]. Available from website http://terbitan.litbang.depkes.go.id/penerbit an/index.php/blp/catalog/download.pdf.

19. Resti Wulandari. Pengaruh Etanol 0$5 \%$ terhadap kekerasan permukaan Resin Komposit Hybrid. 2011. Skripsi Fakultas Kedokteran Gigi USU: tidak diterbitkan.

20. Anusavice KJ. Philips' science of dental material. Eleventh Edition. St.Louis:Saunders. 2006;96-8;471-84.

21. Powers JM, John C Wataha. Dental materials properties and manipulation. Elsavier. 2008;70-72;85-91.

22. Hatrick, Eakle, Bird. Dental Material : clinical application for dental assistant and dental hygienist. St.Louis: Saunders.2003;236-40.

23. John J. Manappalillil. Basic Dental Material. 2nd ed. Jitender:New Delhi.2007;135-40.

24. Anusavice KJ, Ralph W, Shen C. Philips' science of dental material. 12th Edition. St.Louis: Elsavier saunders. 2013;275-304.

25. Susanto AA. Pengaruh ketebalan dan lamanya penyinaran terhadap kekerasan permukaan resin komposit sinat. Dental J. 2000:38(1):32-5.

26. Gordonengland (2013). Vickers Hardness Test.[cited 10:30,5 Desember 2015].Available from website http://www.gordonengland.co.uk/hardness/ Vickers.htm.

27. Wang L, et al. Mechanical properties of dental restoratie materials: relative contribution of laboratory test. $\mathrm{J}$ appl oral sci. 2003:11(3);162-7.

28. Wongkhantee $S$, et al. Effect of acidic food and drinks on surface hardness of enamel, dentine, and tooth-coloured filling materials. J Dent.2005:20(2):1-7.

29. Minuman Ringan yang Beredar di Indonesia. Direktorat Jendral Bea dan Cukai. Soft drinks.[cited 12:00,7 Desember 2015]. Available from website: http://www.beacukai.go.id/library/data/Sof tdrink.htm. 
30. Anggraini Ratri, Sri Yogyarti, Endanus Harijanto. Kekerasan permukaan semen ionomer kaca konvensional dan modifikasi resin setelah perendaman dalam minuman cola. Material Dental Journal. 2011:12(1);26-30.

31. Vanessa M.R, Dinar A.W, Juliatri. Gambaran Kekuatan Tekan bahan tumpatan Semen Ionomer Kaca yang direndam dalam minuman beralkohol. Journal e-GiGi. 2015:1(3);1-6.

32. Chuenarrom C, Benjakul P, Daosodsai P. Effect of Indentation Load and Time on Knoop and Vickers Microhardness Tests for Enamel and Dentin. Materials Research Journal. 2009;12(4):473-6.

33. Mckenzie MA, Linden RWA, Nicholson JW. The effect of Coca-cola and Fruit Juices on The Surface Hardness of Glassionomer and Cmpomers. J Oral Rehabilitation 2004:31(1);146-52.

34. Widodo R. Mengenal minuman ringan berkarbonasi. 2008. [cited 14:28,12 Desember 2015]. Available from website http://www.untag-sby.ac.id.

35. International Organization For Standardization Organisation(ISO). Dentistry-resin based filling material-ISO 4049.1998. [cited 11:20,13 Desember 2015]. Available from website http://www.iso.org/iso/iso_catalogue.htm.

36. Aziz Alimul Hidayat. Metode Penelitian Keperawatan dan Teknik Analisis Data. Edisi pertama. Jakarta:Salemba medika. 2011.36.

37. Shatish C, Shaleen C, Mithlesh C, Girish C, Nidhee C. Dental \& Oral Histology with Embryology \& MCQs. 2nd edition. Jaypee-Higlights Medical Pub Inc. 2010. 54.

38. Da Silva EM, Almeida GS, Poskus LT, Guimaraes JGA. Relationship between the degree of conversion, solubility and salivary sorption of a hybrid and a nanofilled resin composite: Influence of the light-activation mode. J Appl Sci. 2008; 16(2): 161-6.

39. Firoozmand LM, de Araujo MM. Water sorption, hardness and scanning electron microscopy evaluation of dental composite resins submited to high-risk decay model and intensive treatment with flouride. Acta Odontal 2011; 24(2): 141-9.
40. Martos J, Osinaga PWR, Oliveira E, Castro LAS. Hydrolitic degradation of composite resin: effects on the microhadrness. Material Research 2003;6(4):599-604.

41. Ferrance JL. Hygroscopic and hydrolytic effects in dental polymer networks. Dental Materials 2006; 22:211-22.

42. Aguiar FHB, Andrade KRM, Lima DAL, Ambrosano GMB, Lovadino JR. Influence of light curing and sampel thickness on microhardness of a composite resin. Clinical, Cosmetic Investigation Dentistry 2009; 1:21-5.

43. Valinoti AC, Neves BG, Silva EM, Maia LC. Surface degradation of composite resins by acidic medicines and $\mathrm{pH}$-cycling. J App Oral Sci 2008;16(4):257-65.

44. Maganur PDC. Evaluation of microleakage and surface texture of resin modified GIC and flowable composite immersed in soft drink and fresh juice- an in vitro study. Dissertation. Bapuji Dental College and Hospital. India. 2006.

45. Gharatkar AA, Irani R, Viaykumar S, Hegde V.Effect of cola, orange uice and wine on surface micro-hardness of nanocomposites: An in vitro study.J Dent Orofac Res 2014;10(1):16-20.

46. Indrani DJ, Triaminingsih S, Lucky N, Nurvanita A, Yulanti N. Effect of Ethanol in Mouthwashes on The Surface Hardness of a Dental Resin Composite Material. Padjajaran Journal of Dentistry 2009 ; 21(1) : 8-13.

47. Toledano M, et al. Sorption and Solubility of Resin-based Restoratives Dental Materials. Journal of Dentistry 2003 ; 31 : 43-50.

48. L Musanje, Shu M, Darvell BW. Water sorption and mechanical behavior of cosmetic direct restorative materials in artificial saliva. Dental Material 2001;17:394-401.

49. Al-Shekhli AAR, Hakimzadeh SMA. Sorption of nanofilled versus other conventional composites. JIDMR 2012; 5(2): 73-6.

50. Mathias P, Santos SR, Anguiar TR, Santos PR, Cavalcanti AN. Cigarette smoke:effects on water sorption and solubility of restorative dental composites. Operative Dentistry 2013; 3: 54-7. 